\title{
3 Research Square

\section{Usefulness of Lymphocyte ratio and CRP Level for Early Detection of Surgical Site Infection Following spinal surgery}

\section{Wenbo Wei}

Shaanxi Provincial People's Hospital

\section{Shajie Dang}

Shaanxi Provincial Tumor Hospital

Dapeng Duan

Shaanxi Provincial People's Hospital

\section{Liqun Gong}

Shaanxi Provincial People's Hospital

Jue Wang

Xi'an Jiaotong University

Ling Wei ( $\triangle$ wwb560@163.com )

yangling hospital

\section{Research article}

Keywords: surgical site infection, C-reactive protein, white blood cell, lymphocyte, neutrophil, diagnosis

Posted Date: October 4th, 2019

DOl: https://doi.org/10.21203/rs.2.15566/v1

License: (1) This work is licensed under a Creative Commons Attribution 4.0 International License.

Read Full License 


\section{Abstract}

Background: To investigate the significant laboratory markers for early diagnosis of surgical site infection after spinal surgery. And determine the diagnostic cut-off values of these markers

Methods: A total of 67 patients participated in the study: 11 patients who developed surgical site infection after spinal surgery (SSI Group) and 56 patients were compared with the infected group in terms of age『gender, operating time and intraoperative blood loss (Non-SSI Group). The white blood cell (WBC) count, WBC differential , C-reactive protein (CRP) and erythrocyte sedimentation rate(ESR) were determined before and 1, 3 and 7 days postoperatively. Then, we determine the diagnostic cutoff for these markers by using the receiver operating characteristic curve.

Results: The CRP, ESR and WBC were significantly higher in the SSI group at 3 and 7 days postoperatively. The lymphocyte ratio at 3 days postoperatively was significantly lower in the SSI Group. Using the receiver operating characteristic curve冈lymphocyte ratio $<11.5 \%$ at 3 days postoperatively (sensitivity $90.9 \%$, specificity $75.4 \%$, area under the curve [AUC] 0.919 ), and C-reactive protein level $>26 \mathrm{mg} / \mathrm{dL}$ at 7 days postoperatively (sensitivity $90.9 \%$, specificity $87.7 \%$, area under the curve [AUC] 0.954 ) were the significant laboratory marker for early detection of SSI

Conclusion: Lymphocyte ratio $<11.5 \%$ at 3 days and C-reactive protein levels $>26.5 \mathrm{mg} / \mathrm{dl}$ at 7 days after spinal surgery are reliable markers of SSI.

\section{Background}

With the increase of spinal surgery $\llbracket$ Surgical site infection (SSI), which was first described as a clinical entity by Turnbull in $1953^{1}$, remains a common and costly complication of spinal surgery. SSI infection rates of 0.7 to $16 \%$ after instrumented spinal fusion have been reported ${ }^{2,3}$. Complications associated with SSI after spinal surgery include pseudoarthrosis, deterioration of neurological function, sepsis, and even death.

When Surgical site infection does occur, early diagnosis and treatment will greatly improve outcomes and shorten post-operative recovery. It should be based on indicators of systemic infection, laboratory data, imaging techniques ${ }^{4-7}$, and local findings such as tenderness, swelling, redness, and purulent discharge ${ }^{8}$ to diagnose SSI. Of the clinical findings associated with SSI, there are several laboratory markers available for early detection because of their objectivity and convenience, For instance, C-reactive protein (CRP), erythrocyte sedimentation rate(ESR) and white blood cell (WBC) count and differential count ${ }^{8-10}$.

Hence, we consider that reliable laboratory markers are needed for the early detection of SSI after spine decompression surgery. The present study aimed to identify the most signicant laboratory marker and to determine an appropriate cut-off values for these diagnostic markers using receiver operating characteristic (ROC) curve for early detection of SSI. 


\section{Methods}

The study protocol was approved by the institutional review board of Shaanxi Provincial People's Hospital(Clinical ethics committee of Shaanxi People's Hospital (2014), No.027.). We retrospectively reviewed 67 patients who underwent spinal surgery at the Department of Orthopedic Surgery, Shaanxi Provincial people's Hospital, between January 2015 and June 2018. SSI was determined according to U.S Centers for Disease Control and Prevention criteria11. We recorded patients as SSI patients, if the surgeon performed debridement, conducted positive blood cultures, or drained surgical wounds. Patients were excluded if they had a trauma, tumor, or infection at the time of surgery or previous surgery of the lumbar spine, or were under 20 years of age. We also excluded patients who did not undergo laboratory tests on 1,3 and 7 days after surgery.

We collected data include CRP, ESR, WBC count, and neutrophil and lymphocyte ratio before surgery and 1,3 , and 7 days postoperatively. CRP and ESR were measured by latex agglutination method, and WBC was measured by automatic cell counter. The ratio of neutrophils and lymphocytes was calculated from WBC percentage difference.

Statistical analyses were conducted using IBM SPSS 12.0 for Windows (Microsoft Corporation, Redmond WA). Data are expressed as mean \pm standard deviations (SDs). Continuous variables are presented as means and standard deviations. Categorical variables are summarized as the number and percentage of the total study population. Normally distributed continuous variables were compared with a two-sided independent t-test. Categorical variables were combined with Chi-square. We determined appropriate diagnostic cutoffs of these selected markers using the ROC curve. Statistical significance was defined as $P<0.05$.

\section{Results}

Demographics and Operative Circumstances

The final sample consisted of 67 patients and was divided into 11 patients who developed deep SSI (SSI group) and 56 who did not (non-SSI group). 7 male and 4 female were included in the SSI group, while 23 male and 33 female were in the non-SSI group. Mean age of pa- tients in the SSI Group was 55.82 \pm 20.89 years and in the non-SSI group was $55.55 \pm 14.43$ years. Operating time in the SSI group was $223.64 \pm 90.36$ minutes (range 120 420), and in the non-SSI group was $189.74 \pm 80.70$ minutes (range 60 450); intraoperative blood loss in the SSI group was $600.00 \pm 303.32 \mathrm{ml}$ (range 200 1000), and in the non SSI group was $442.11 \pm 251.21 \mathrm{ml}$ (range 100 1000). There were no significant differences in the age, sex, operating time, and intraoperative blood loss between the two groups (Table 1).

\section{Outcomes in the SSI Group}

With the $11 \mathrm{SSI}$ patients, 10 patients conducted debridement, 8 of them removed their instrumentation. The other 1 patient had antibiotics treated without surgury. In 10 patients who underwent reoperation, the 
responsible bacteria (staphylococcus aureus in 4 cases, klebsiella pneumonia in 3 cases, pseudomonas aeruginosain 2 cases and 1 unknown) were detected at the surgical site.). The blood culture result of drug-treated patients is Staphylococcus aureus.

After surgery or medication treated囚all patients recovered (Table 2).

Biochemical Markers

There were no significant differences between the SSI and no-SSI groups for all chemical markers before surgery. Post-operative 1 day, the WBC count in the SSI group (15.65 \pm 6.05$)$ was significantly higher compared to the no-SSI group $(12.07 \pm 3.95)(t=-2.51, p=0.01)$, but there was no significant differences in CRP, ESR, neutrophil ratio and lymphocyte ratio.(Fig.1)

Post-operative 3 day(Fig.2), the WBC count in the SSI group (12.55 \pm 3.78$)$ was no significant differences compared to the no-SSI group $(10.29 \pm 3.65)(t=-1.69, p=0.096)$. The neutrophil ratio in the SSI group $(0.84 \pm 0.07)$ was significantly higher compared to the no-SSI group $(0.75 \pm 0.10)(t=-2.77, p=0.007)$. The lymphocyte ratio in the SSI group $(0.06 \pm 0.03)$ was significantly lower compared to the no-SSI group $(0.16 \pm 0.06)(t=4.94, p<0.001)$. The CRP in the SSI group (116.27 \pm 72.84$)$ was significantly higher compared to the no-SSI group $(26.93 \pm 23.16)(t=-7.64, p<0.001)$. The ESR in the SSI group $(64.27 \pm$ 26.67) was significantly higher compared to the no-SSI group (37.96 \pm 24.28$)(t=-3.24, p=0.002)$.

Post-operative 7 day(Fig.3), there was no significant differences in the WBC count. The neutrophil ratio in the SSI group $(0.79 \pm 0.10)$ was significantly higher compared to the no-SSI group $(0.72 \pm 0.10)(\mathrm{t}=--$ $2.391, p=0.020)$. The lymphocyte ratio in the SSI group $(0.12 \pm 0.07)$ was significantly lower compared to the no-SSI group $(0.18 \pm 0.09)(t=2.267, p=0.027)$. The CRP in the SSI group $(118.27 \pm 63.68)$ was significantly higher compared to the no-SSI group $(17.68 \pm 24.65)(t=-5.165, p<0.001)$. The ESR in the SSI group $(63.91 \pm 33.06)$ was significantly higher compared to the no-SSI group (36.46 \pm 27.23$)(\mathrm{t}=-$ $2.957, p=0.004)$.

The ROC curve was used to determine the appropriate diagnostic cut-off values for important laboratory markers. The results are as follows:lymphocyte ratio 3 days postoperatively, cutoff $<11.50 \%$ (sensitivity $90.9 \%$, specificity $75.4 \%$, area under the curve [AUC] 0.919; Figure 4.A)); CRP level 7 days postoperatively, cutoff $=26 \mathrm{mg} / \mathrm{dL}$ (sensitivity $90.9 \%$, specificity $87.7 \%$, area under the curve [AUC] 0.954 ; Figure 4.B).

\section{Discussion}

Although large-scale efforts have been initiated to help mitigate postoperative SSIs after spine surgery, a sizable burden still exists. The incidence of spinal SSI is between $0.7 \%$ and $16 \%$, depending on the type of surgery and the area involved ${ }^{2,3}$. The postoperative course complicated by SSI may entail long and repeated hospitalizations and multiple surgical interventions, including irrigation and debridement, removal of hardware, and complex wound closure. So early diagnosis and treatment would greatly improve results and shorten post-operative recovery. 
However, not all patients can afford additional assessments (e.g. CT, MRI, PET) because these methods are very expensive and requires a lot of time ${ }^{13-15}$. Therefore, postoperative laboratory markers are often used to screen SSI due to their objectivity, low cost and convenience ${ }^{12,16}$.

The most widely used biochemical markers for early diagnosing SSI are CRP, ESR, and the WBC count and differential. The difference between ESR and CRP increases after surgery can distinguish between infected and non-infected patients. Larsson et $\mathrm{al}^{17}$. were the first to report changes in the CRP level in lumbar posterior lumbar surgery. they found that the level reached to peak on post-operative day 3 , and dropped to normal (less than $10 \mathrm{mg} / \mathrm{l}$ ) within 21 days after surgery. However, Takahashi et al ${ }^{18}$. reported that the postoperative CRP level peaked on day 2 , and Aono et $\mathrm{al}^{19}$. reported that it peaked on day 4 . The peak postoperative CRP levels should be between the 2 nd and 4th day after surgery. It is believed that CRP levels have risen again or are still at peak levels 5 days after surgery, suggesting that SSI is more likely to occur.In our result, we found that the level of CRP in the SSI group increased significantly 3 days after operation and remained high 7 days after operation. CRP in non-infectious group increased significantly 3 days after operation and decreased gradually 7 days after operation (Fig.1 D). ESR in infection group and non-infection group increased significantly 3 days after operation, but decreased slightly 7 days after operation(Fig. 1 E). Erythrocyte sedimentation rate increased to peak levels about five days after surgery, followed by a slow and irregular decrease ${ }^{17}$. Therefore, CRP is more suitable than ESR for evaluating infection. In our research, one day after operation, CRP increased in all patients. In non-SSI patients, CRP began to decline on days 3 and 7 after surgery. However, in infected patients, the third day after surgery increased further and decreased on the 7th day after surgery. We determine the diagnostic cutoff for CRP by using the receiver operating characteristic curve. If CRP is still $>26 \mathrm{mg} / \mathrm{dl}$ in 7 days after operation, infection should be highly suspected and antibiotics should be changed or increased.

Several factors have been reported in the literature that affect postoperative CRP levels, including blood loss, preoperative CRP levels, and spinal surgery segments. For example, surgery in the lumbar region is associated with higher postoperative CRP levels compared to surgery in other areas. ${ }^{20}$. Given the uncertainty of the use of inflammatory markers as a diagnostic tool for SSI, additional tools are needed to distinguish between infected and non-infected patients at the postoperative stage.

Takahashi et al ${ }^{21}$ reported for the first time that the WBC counts and lymphocyte counts are helpful for early diagnosis of surgical wound infections after lumbar surgery. In this article lymphocyte ratio no more than $10 \%$ or count less than $1,000 / L$ at 4 days after surgery indicates possible surgical wound infection. The authors suggest that lymphocytopenia represents an immunosuppressive state, indicating that the body's susceptibility to infection increases, which may lead to the development of postoperative infection. After that, More and more scholars make a profound study at this field. Iwata et al showed that the lymphocyte count of $<1,000 / \mu \mathrm{L}$ at 4 days postoperatively was the sole significant independent laboratory marker for early detection of SSI ${ }^{16}$. Chao-Jun Shen et al reported ${ }^{22}$ that neutrophil/lymphocyte count ratio (NLR)at 4 and 7days post-operation are valuable laboratory predictors for SSI in patients with posterior lumbar spinal surgery. ROC results showed that NLR> 5.19 at 4 days $₫$ the sensitivity and 
specicity of the NLR were $61.5 \%$ and $77.6 \%$, the AUC was 0.708 and NLR> 3.85 at 7 days $囚$ the sensitivity and specicity of the NLR were $69.2 \%$ and $62.7 \%$; the AUC was 0.663 .

In our result one day after surgical invasion, neutrophils increase and lymphocytes decrease in all patients. In non-SSI patients, neutrophils begin to decrease and lymphocytes increase on day 3 after surgery. However, in infected patients, further increase in neutrophils and decrease in lymphocytes were detected on day 3(Fig.1 B.C). Therefore, we determine the diagnostic cutoff for lymphocytes ratio by using the receiver operating characteristic curve. If the lymphatic ratio was less than $11.5 \%$ at 3 days after operation, and infection was highly suspected, which was similar to the previous literature. This may be an important indicator of SSI after posterior lumbar surgery.

Based on the results of the study, we analyzed the sensitivity and specificity of five laboratory indicators for early detection of SSI. There are two laboratory markers to be founded for its sensitivity and specificity. The first indicator was CRP level $>26 \mathrm{mg} / \mathrm{dl}$ on day 7 after surgery, the sensitivity and specificity were $90.9 \%$ and $87.7 \%$, the AUC was 0.954 . the other indicator was lymphocyte ratio $<11.50 \%$ on the third day after surgery. the sensitivity and specificity were $90.9 \%$ and $75.4 \%$, the AUC was 0.919 .

Our research has several limitations. First, this is a retrospective study. Therefore, there may be inherent bias associated with patient selection and missing patient information. Second, chronic SSI patients may be included in the non-SSI group because they only focus on the results of the hospitalization exam, which may reflect a serious underestimation of the actual number of SSI cases. In future studies, we will expand into the population and follow-up time, and hope to reduce these problem.

\section{Conclusion}

In conclusion, the lymphocyte ratio at 3 days postoperatively with a cutoff of $<11.50 \%$, and CRP level at 7 days postoperatively with a cutoff of $>26 \mathrm{mg} / \mathrm{dL}$,are the most reliable laboratory markers for early SSI following lumbar surgery, because they have a high sensitivity and can be measured early.

\section{Abbreviations}

SSI $₫$ Surgical site infection; WBC: white blood cell; CRP:C-reactive protein; ESR: erythrocyte sedimentation rate; AUC: area under the curve; ROC: receiver operating characteristic

\section{Declarations}

\section{Consent for publication}

$\mathrm{N} / \mathrm{A}$

\section{Acknowledgements}


We greatly appreciate the assistance of the company Medjaden Bioscience Limited., which provided English language editing.

\section{Availability of data and materials}

All data generated or analyzed during this study are included in this article. We confirm that the Availability of data and materials refers to the raw data generated and used for this study. Meanwhile, the datasets used and/or analyzed during the current study are available from the corresponding author on reasonable request.

\section{Authors' contributions}

WBW was in charge and contributed to all stages of the present study.; DPD and LQG were responsible for participated in the design of the study, made revisions of the manuscript and approved the final version. WBW and SJD contributed to interpreting the data and writing the final manuscript; LW and JW were contributor in writing and editing the manuscript. All authors read and approved the final manuscript.

\section{Funding}

No funding was obtained for this study

\section{Ethics approval and consent to participate}

The study protocol was approved by the Institutional Review Board of Shaanxi provincial people Hospital (the ethics approval number provided by the board was (2014), No.027), and written informed consent was obtained from all study participants.

\section{Competing interests}

The authors declare that they have no competing interests.

\section{Reference}

1.Yao Reina, Tan Terence, Tee Jin Wee, et al. Prophylaxis of surgical site infection in adult spine surgery: A systematic review.. J Clin Neurosci. 2018;52:5-25.

2.Gande Abhiram, Rosinski Alex, Cunningham Torin, et al. Selection pressures of vancomycin powder use in spine surgery: a meta-analysis.. Spine J. 2019;19(6):1076-1084. 
3.Cheng Christina W, Cizik Amy M, Dagal Armagan H C, et al. Body mass index and the risk of deep surgical site infection following posterior cervical instrumented fusion.. Spine J. 2019;19(4):602-609.

4.Janssen Daniël M C, van Kuijk Sander M J, d'Aumerie Boudewijn, et al. A prediction model of surgical site infection after instrumented thoracolumbar spine surgery in adults.. Eur Spine J. 2019;28(4):775782.

5.Zakaria Hesham Mostafa, Bazydlo Michael, Schultz Lonni, et al. Adverse events and their risk factors 90 days after cervical spine surgery: analysis from the Michigan Spine Surgery Improvement Collaborative.. J Neurosurg Spine. 2019;:1-13.

6.H. Inanami, Y. Oshima, T. Iwahori, et al., Role of 18F-fluoro-D-deoxyglucose PET/ CT in diagnosing surgical site infection after spine surgery with instrumentation, Spine (Phila Pa 1976) 40 (2) (2015) 109113.

7.Pesenti Sebastien, Pannu Tejbir, Andres-Bergos Jessica, et al. What are the risk factors for surgical site infection after spinal fusion? A meta-analysis.. Eur Spine J. 2018;27(10):2469-2480.

8.Iwata Eiichiro, Shigematsu Hideki, Yamamoto Yusuke, et al. Lymphocyte Count at 4 Days Postoperatively: A Reliable Screening Marker for Surgical Site Infection After Posterior Lumbar Decompression Surgery.. Spine (Phila Pa 1976). 2018;43(18):E1096-E1101.

9.Kang Byung-Uk, Lee Sang-Ho, Ahn Yong, et al. Surgical site infection in spinal surgery: detection and management based on serial C-reactive protein measurements.. J Neurosurg Spine. 2010;13(2):158-64.

10.Sebaaly Amer, Shedid Daniel, Boubez Ghassan, et al. Surgical site infection in spinal metastasis: incidence and risk factors.. Spine J. 2018;

11.Berríostorres SI, Umscheid CA, Bratzler DW, et al. Centers for Disease Control and Prevention Guideline for the Prevention of Surgical Site Infection, 2017. Jama Surgery 2017;152:784.

12.K. T. Kang, D. W. Son, S. H. Lee, et al., Variation of C-reactive protein and white blood cell counts in spinal operation: primary fusion surgery versus revision fusion surgery, Korean J. Spine 14 (3) (2017) 6670. 凶

13.Rankine JJ. The Postoperative Spine. Topics in Magnetic Resonance Imaging Tmri 2014;18:300-8.

14. Hirohiko I, Yasushi O, Tomoyuki I, et al. Role of 18F-fluoro-D-deoxyglucose PET/CT in diagnosing surgical site infection after spine surgery with instrumentation. Spine 2015;40:109-13.

15.Wang Y, Cheung PY, Cheung MC. Use of PET/CT in the early diagnosis of implant related wound infection and avoidance of wound debridement. European Spine Journal 2016;25:38-43. 
16.Iwata E, Shigematsu H, Okuda A, et al. Lymphopenia at 4 Days Postoperatively Is the Most Significant Laboratory Marker for Early Detection of Surgical Site Infection Following Posterior Lumbar Instrumentation Surgery. Asian Spine Journal 2016;10:1042-6.

17.Larsson S, Thelander U, Friberg S. C-reactive protein (CRP) levels after elective orthopedic surgery. Clinical orthopaedics and related research 1992;275:237-42.

18.Takahashi J, Ebara S, Kamimura M, et al. Early-phase enhanced inflammatory reaction after spinal instrumentation surgery. Spine 2001;26:1698-704.

19.Mok JM, Pekmezci M, Piper SL, et al. Use of C-reactive protein after spinal surgery: comparison with erythrocyte sedimentation rate as predictor of early postoperative infectious complications. Spine 2008;33:415.

20.Kang Byung-Uk, Lee Sang-Ho, Ahn Yong, et al. Surgical site infection in spinal surgery: detection and management based on serial C-reactive protein measurements.. J Neurosurg Spine. 2010;13(2):158-64.

21. J. T akahashi, Y. Shono, H. Hirabayashi, et al., Usefulness of white blood cell differential for early diagnosis of surgical wound infection following spinal instrumentation surgery, Spine (Phila Pa 1976) 31 (9) (2006) 1020-1025. 区

22.Shen Chao-Jun, Miao Tao, Wang Zhang-Fu, et al. Predictive value of post-operative neutrophil/lymphocyte count ratio for surgical site infection in patients following posterior lumbar spinal surgery.. Int Immunopharmacol. 2019;74:105705.

\section{Tables}

Table 1. Comparison of demographic data in patients

\begin{tabular}{|c|c|c|c|c|}
\hline \multicolumn{2}{|l|}{ - } & $\underset{(\mathrm{n}=62)}{\text { Group Non-SSI }}$ & $\begin{array}{c}\text { Group } \\
\text { SSI } \\
(\mathrm{n}=11)\end{array}$ & $P$ \\
\hline \multicolumn{2}{|c|}{ Age (years) } & $55.55 \pm 14.43$ & $55.82 \pm 20.89$ & \multirow{3}{*}{$\begin{array}{l}0.958 \\
0.296\end{array}$} \\
\hline \multirow[t]{2}{*}{ Sex } & Male & 23 & 7 & \\
\hline & Female & 33 & 4 & \\
\hline \multirow{2}{*}{\multicolumn{2}{|c|}{$\begin{array}{l}\text { Operating time (min) } \\
\text { blood loss } \llbracket \mathrm{ml} \square\end{array}$}} & $189.74 \pm 80.70$ & $223.64 \pm 90.36$ & 0.215 \\
\hline & & $442.11 \pm 251.21$ & $600.00 \pm 303.32$ & 0.069 \\
\hline
\end{tabular}

Notes: Values are expressed as mean \pm SD and the number of patients (\%).

Table 2. Comparison of demographic data in patients

\section{Figures}




\begin{tabular}{|c|c|c|c|c|c|}
\hline $\begin{array}{l}\text { Patient } \\
\text { No. }\end{array}$ & $\begin{array}{l}\text { Age } \\
(\mathrm{yr})\end{array}$ & Sex & $\begin{array}{l}\text { Method of } \\
\text { Diagnosis }\end{array}$ & Culture & Method of Treatment \\
\hline 1 & $40-50$ & Male & Debridement & $\begin{array}{l}\text { staphylococcus } \\
\text { aureus }\end{array}$ & $\begin{array}{l}\text { Debridement, implant } \\
\text { removal }\end{array}$ \\
\hline 2 & $60-70$ & Male & Debridement & Unknown & Debridement \\
\hline 3 & $60-70$ & Male & Wound drainage & klebsiella pneumonia & $\begin{array}{l}\text { Debridement, implant } \\
\text { removal }\end{array}$ \\
\hline 4 & $60-70$ & Male & Debridement & $\begin{array}{l}\text { staphylococcus } \\
\text { aureus }\end{array}$ & $\begin{array}{l}\text { Debridement, implant } \\
\text { removal }\end{array}$ \\
\hline 5 & $20-30$ & Male & Debridement & $\begin{array}{l}\text { staphylococcus } \\
\text { aureus }\end{array}$ & Antibiotic medication \\
\hline 6 & $60-70$ & Male & Debridement & klebsiella pneumonia & $\begin{array}{l}\text { Debridement, implant } \\
\text { removal }\end{array}$ \\
\hline 7 & $20-30$ & Male & Wound drainage & $\begin{array}{l}\text { pseudomonas } \\
\text { aeruginosa }\end{array}$ & Debridement \\
\hline 8 & $60-70$ & Female & Debridement & $\begin{array}{l}\text { staphylococcus } \\
\text { aureus }\end{array}$ & $\begin{array}{l}\text { Debridement, implant } \\
\text { removal }\end{array}$ \\
\hline 9 & $80-90$ & Female & Wound drainage & $\begin{array}{l}\text { pseudomonas } \\
\text { aeruginosa }\end{array}$ & $\begin{array}{l}\text { Debridement, implant } \\
\text { removal }\end{array}$ \\
\hline 10 & $70-80$ & Female & Debridement & klebsiella pneumonia & $\begin{array}{l}\text { Debridement, implant } \\
\text { removal }\end{array}$ \\
\hline 11 & $40-50$ & Female & Debridement & $\begin{array}{l}\text { staphylococcus } \\
\text { aureus }\end{array}$ & $\begin{array}{l}\text { Debridement, implant } \\
\text { removal }\end{array}$ \\
\hline
\end{tabular}


A

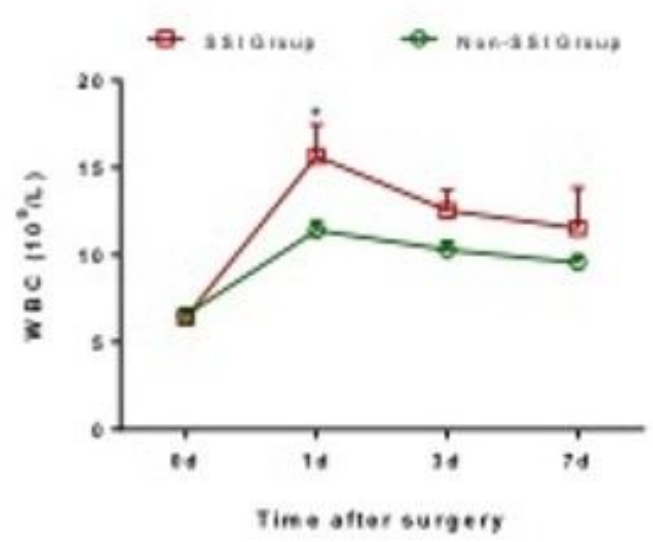

c

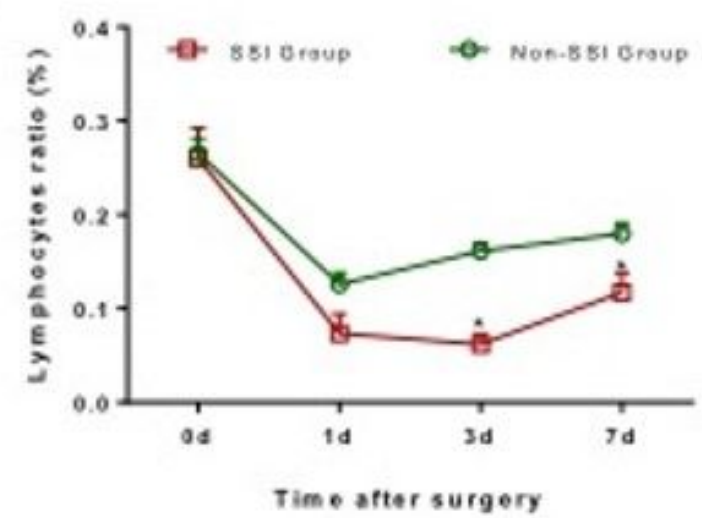

E

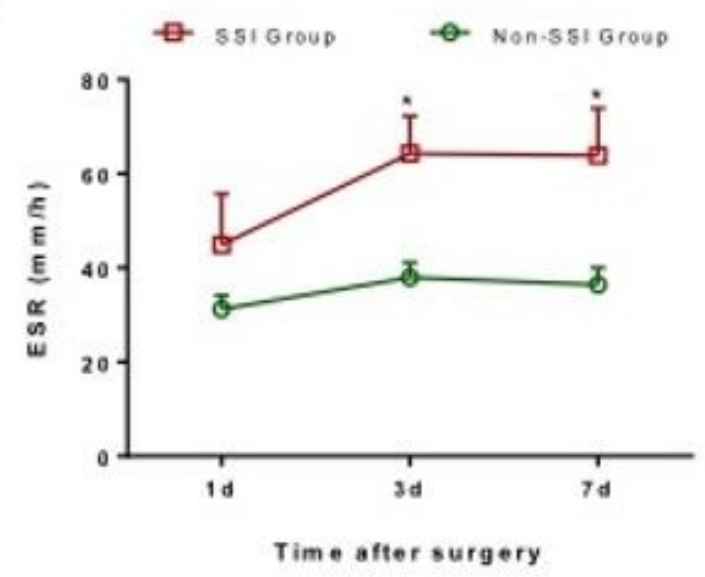

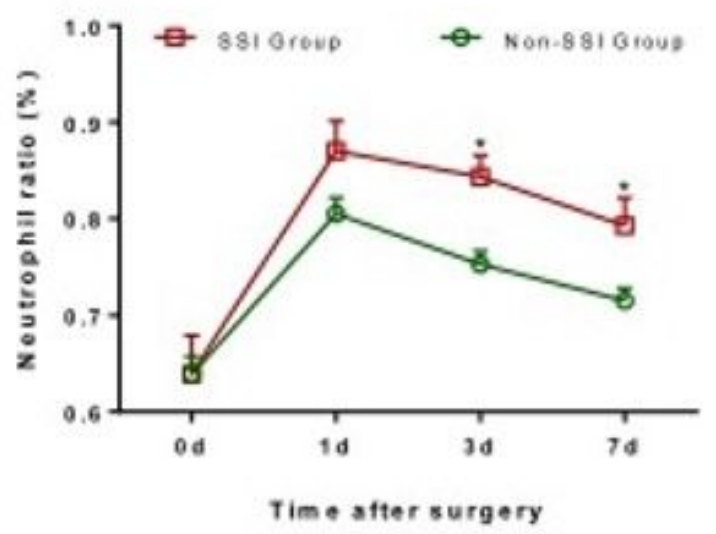

D

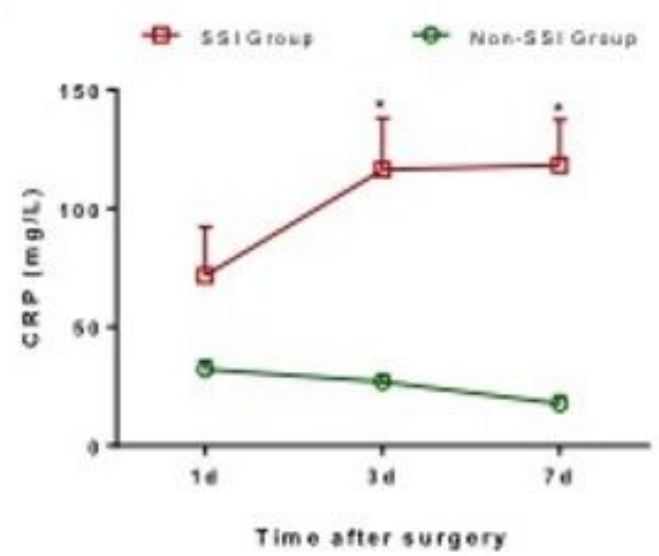

Figure 1

A. WBC-time profile ( $\left.{ }^{\star} P<0.05\right)$. B. Neutrophil \%-time profile $\left({ }^{\star} P<0.05\right)$. C. Lymphocyte \%-time profile ( ${ }^{\star} P<$ $0.05)$ D.CRP-time profile $\left({ }^{\star} P<0.05\right)$. E. ESR-time profile $\left({ }^{*} P<0.05\right)$ 
B

A

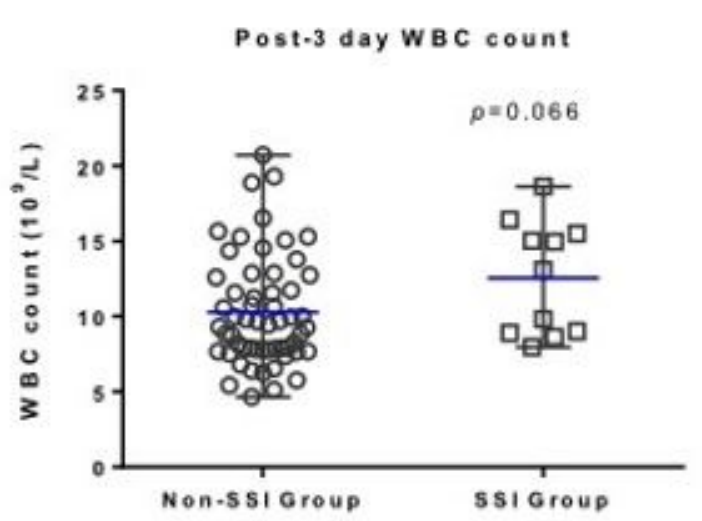

C

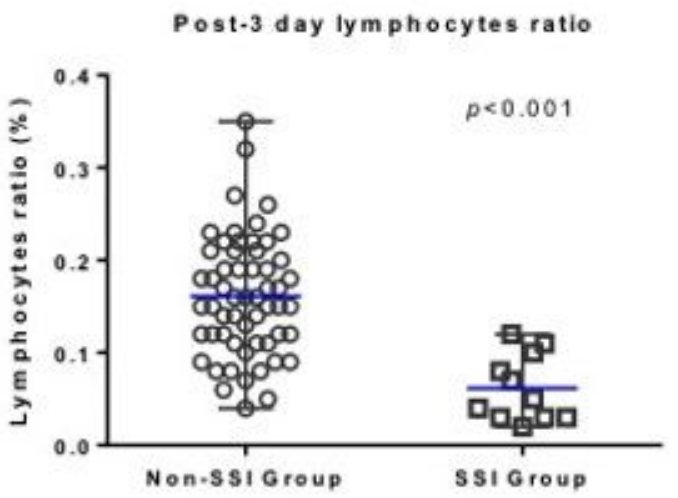

E

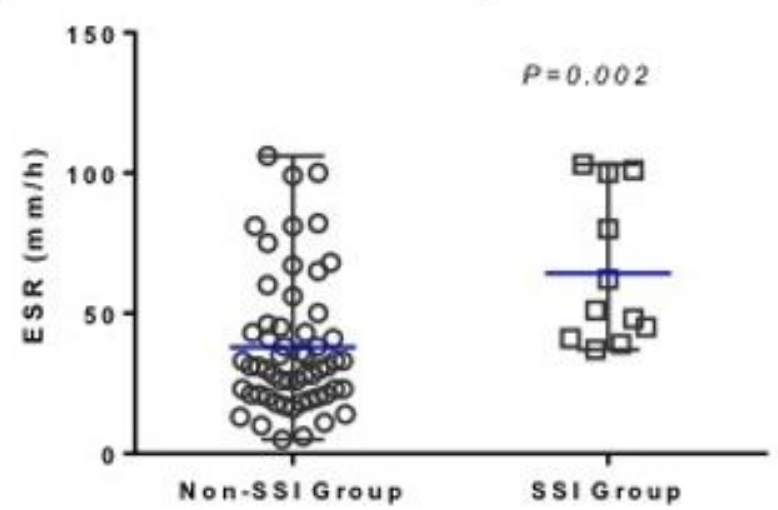

Post-3 day Neutrophil ratio

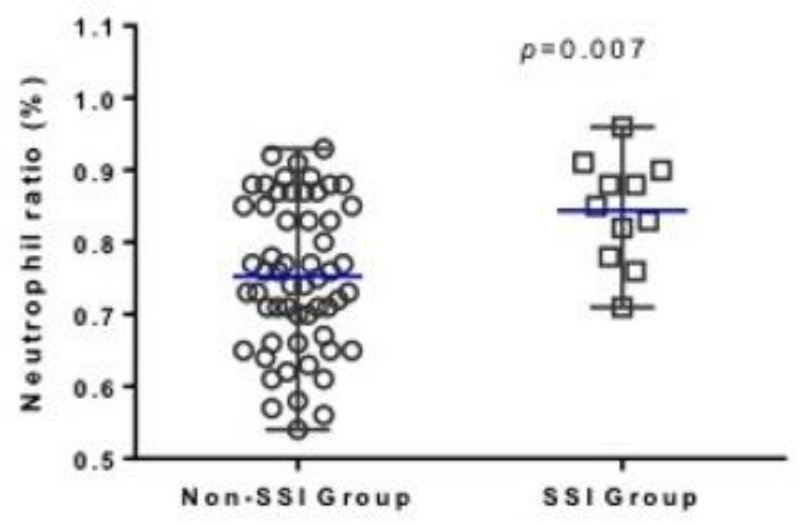

D

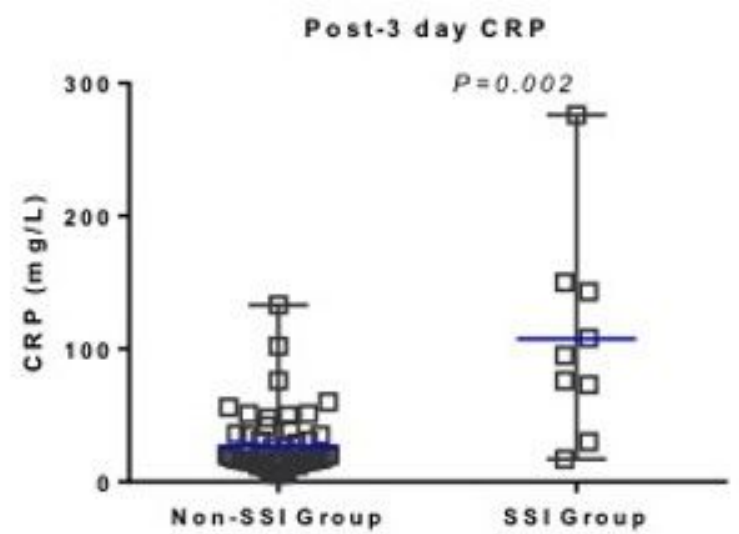

\section{Figure 2}

The distribution and comparison of 3-days post-operative laboratory variables between the patients with SSI ( $n=11)$ and non-SSI ( $n=56)$ patients. (A) WBC count; (B) neutrophil ratio; (C) lymphocyte ratio; (D) CRP; (E) ESR.The blue line represents the median values. All comparisons were performed with the MannWhitney U test. 
A

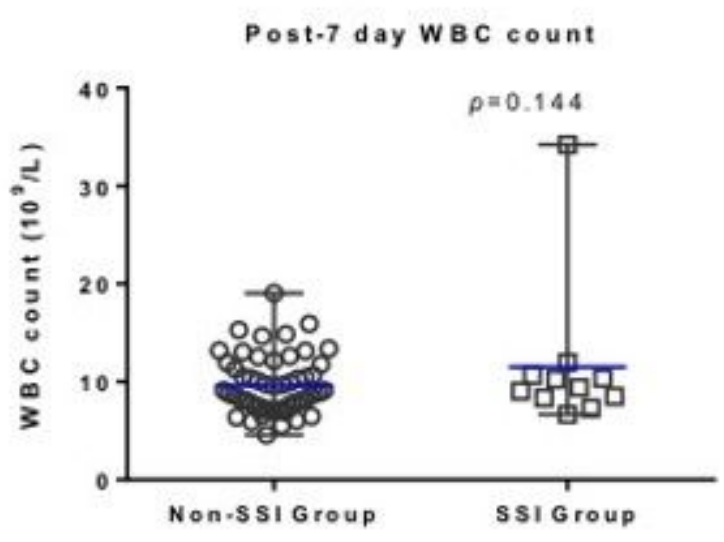

C

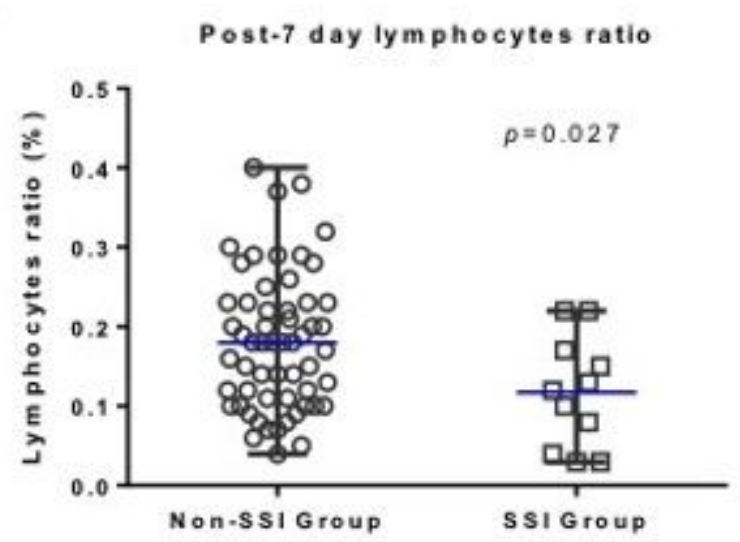

E

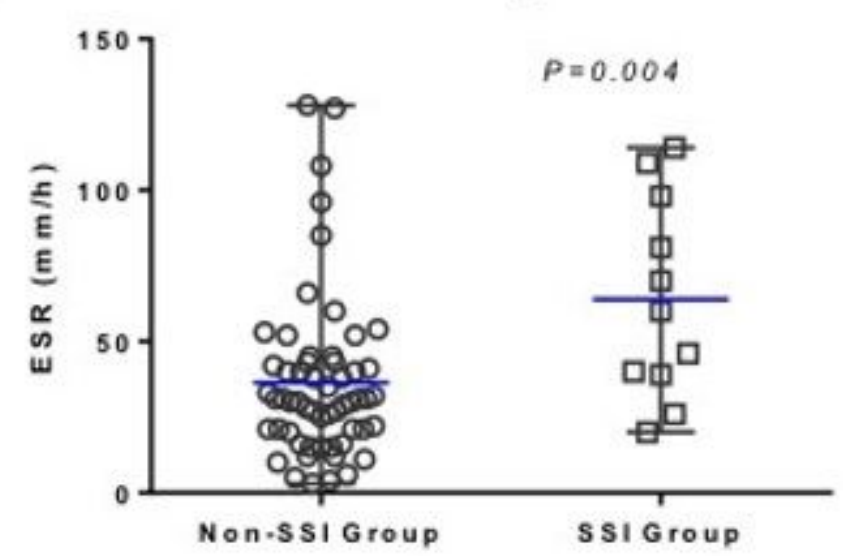

B

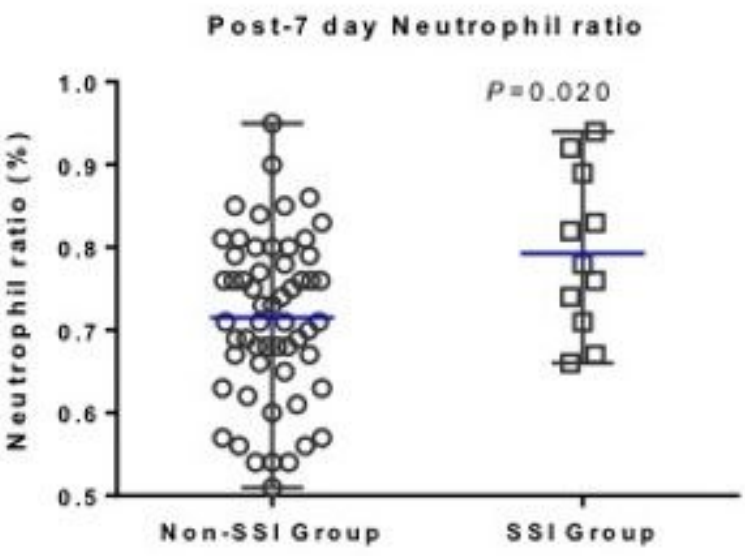

D Post-7 day CRP

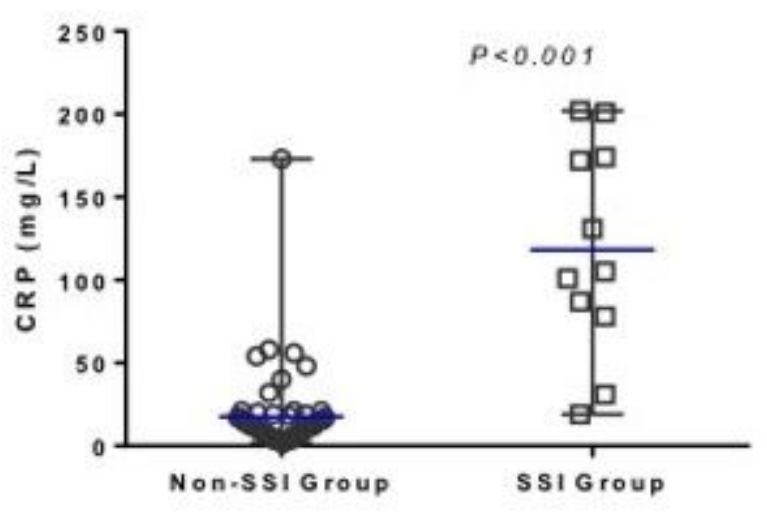

\section{Figure 3}

The distribution and comparison of 7-days post-operative laboratory variables between the patients with SSI ( $n=11)$ and non-SSI ( $n=56)$ patients. (A) WBC count; (B) neutrophil ratio; (C) lymphocyte ratio; (D) CRP; (E) ESR.The blue line represents the median values. All comparisons were performed with the MannWhitney U test. 
A

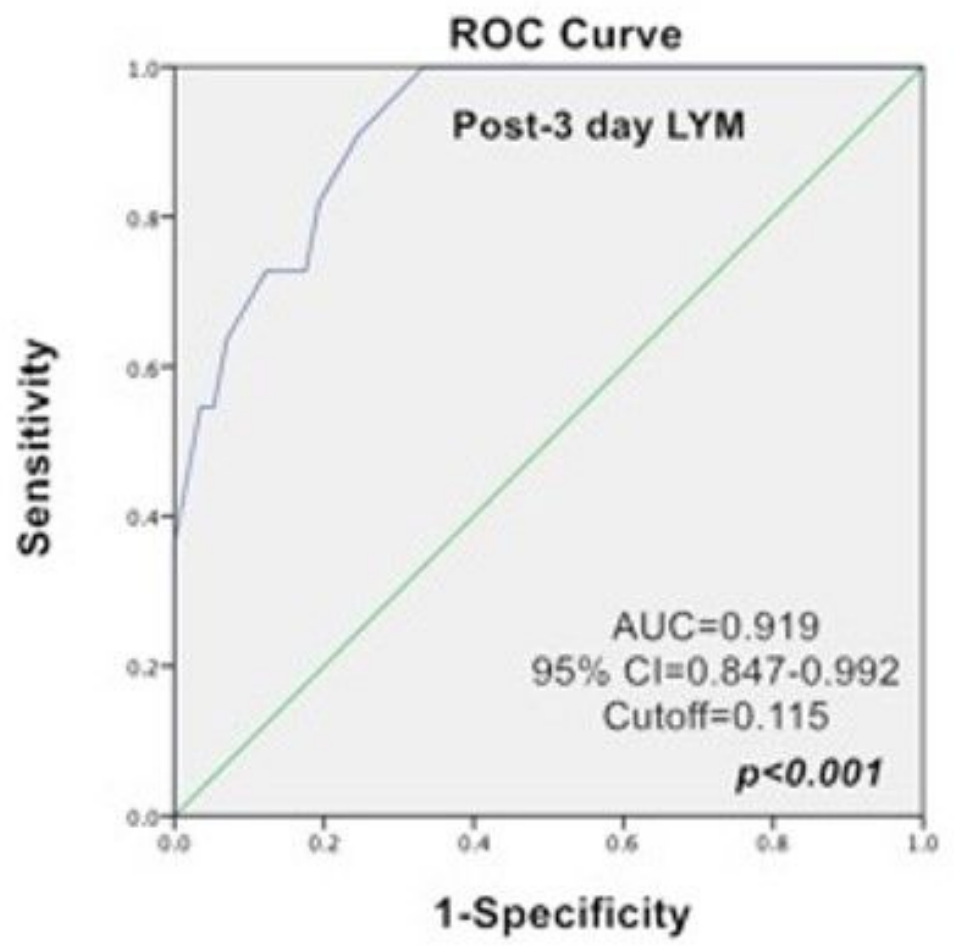

B

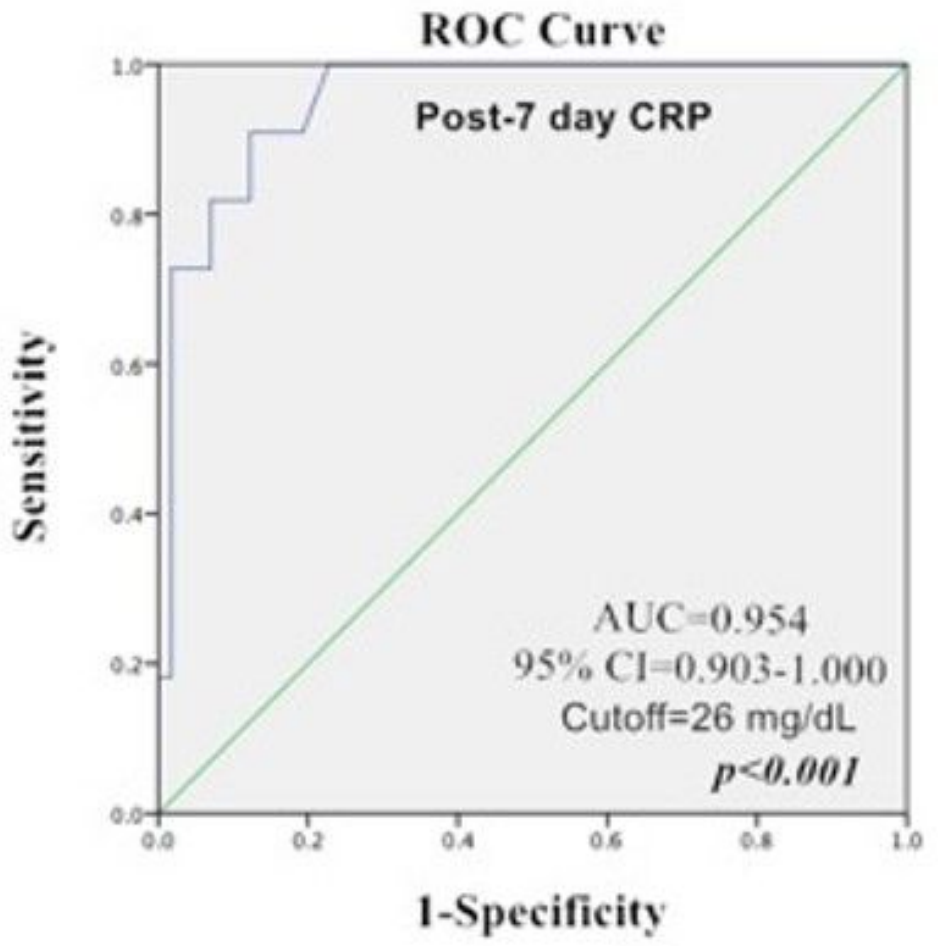

Figure 4

ROC analysis for lymphocyte ratio at 3 -days post-operation (A) and CRP at 7 -days post-operation (B). 